\title{
Sex Dependence of Cognitive Functions in Bipolar Disorder
}

\author{
Aleksandra Suwalska and Dorota Kojko \\ Department of Adult Psychiatry, University of Medical Sciences, 60-572 Poznań, Poland \\ Correspondence should be addressed to Dorota Łojko; d.lojko@hotmail.com
}

Received 31 August 2013; Accepted 11 November 2013; Published 29 January 2014

Academic Editors: J. H. Beitchman and A. J. Torres

Copyright (C) 2014 A. Suwalska and D. Łojko. This is an open access article distributed under the Creative Commons Attribution License, which permits unrestricted use, distribution, and reproduction in any medium, provided the original work is properly cited.

\begin{abstract}
The objective of the present study was to assess the performance of lithium treated euthymic bipolar patients in tests measuring spatial working memory (SWM), planning, and verbal fluency and to delineate the influence of gender on cognitive functioning. Fifty-nine euthymic bipolar patients, treated with lithium carbonate for at least $5 \mathrm{yr}$, were studied. Patients and controls underwent a neuropsychological assessment. Bipolar patients had significantly worse results than the healthy controls in the spatial memory and planning as well as verbal fluency tests. We detected a gender-related imbalance in the SWM results. Deficits in SWM were observed in male-only comparisons but not in female-only comparisons. The SWM scores were significantly poorer in male patients than in male controls. In female-only comparisons, female patients did not have significantly poorer SWM results in any category than their controls. Bipolar women scored worse in some other tests. The present study points to the different patterns of neuropsychological disturbances in female and male patients and suggests that sex-dependent differences should be taken into account in order to tailor the therapeutic intervention aimed at the improvement of cognitive functions.
\end{abstract}

\section{Introduction}

Bipolar disorder (BD) is a chronic and impairing mental disorder with estimated lifetime prevalence in general population of around $2.0 \%: 1.0 \%$ for BD type I (with a history of mania) and $1.1 \%$ for BD type II (with a history of hypomanic episodes only) [1,2]. Bipolar disorder has been recognized as one of the most significant causes of increased mortality and morbidity due to mental illnesses [3]. The symptomatology of BD involves affective disturbances, cognitive deficits, and high rates of somatic and psychiatric comorbidity [4]. BD is a complex and heterogeneous illness.

The results of the studies investigating the prognostic role of gender in $\mathrm{BD}$ are inconsistent [1]. The majority of studies have reported equal prevalence of bipolar disorder (BD) in men and women, whilst bipolar II disorder is more frequent among females $[5,6]$. Most studies report an increased risk of rapid cycling and mixed episodes in women [6]. Men usually present with manic episodes and have comorbid drug abuse, while women usually present with major depressive episode [7]. However, some authors have reported that the number of affective episodes of any polarity does not differ across gender [5]. Whereas some authors have noticed a later onset of bipolar disorder in women than in men [7], others have not noticed such a difference [5].

Women are more prone to experience mixed or dysphoric episodes and to present with seasonal pattern and rapid cycling [8] and tend to experience atypical depressive symptoms such as weight gain and hypersomnia [9]. Bipolar women more frequently have comorbid somatic illnesses, particularly thyroid diseases, migraine, and obesity [9], and tend to have more comorbid eating disorders, anxiety disorders [7], and bulimia [10], but lower rates of comorbid alcohol and cannabis abuse/dependence [9]. Female gender is associated not only with better medication adherence in bipolar disorder $[9,11,12]$, but also with treatment refractory depression [9].

An association between bipolar disorder and cognitive impairment has repeatedly been described, even for euthymic patients [13]. Nowadays, the old Kraepelinian idea that bipolar patients, unlike those with schizophrenia, do not experience cognitive decline is known not to be true. Cognitive impairment, and especially executive dysfunction, has been recognized in BD patients. They experience neuropsychological disturbances during manic and depressive episodes and during remission periods [14-16]. Several metaanalyses 
[17-23] have provided evidence for trait deficits in verbal memory, and learning, executive functions, working memory, and response inhibition in remitted bipolar patients. The persistence of poor performance in these tasks in euthymic adult patients and in their unaffected relatives suggests that these specific cognitive impairments may be $\mathrm{BD}$ endophenotypes [24-26]. In healthy population, sexual dimorphism in cognitive functioning is well known and widely described. The classical dichotomy claims that men are better at spatial abilities and women at verbal skills.

Some studies investigating sex differences in spatial working memory have recently brought equivocal results [27] with men outperforming women only as regards the visuospatial component of the spatial rotation test. Men performed more quickly and with a greater accuracy in navigation tests $[28,29]$. Several studies indicate that in tasks involving remembering objects in an array, women outperform men. A female advantage is described in tasks of verbal memory, episodic and autobiographical memory, some tasks involving processing speed and emotional memory [27]. Female patients are superior to male patients in verbal memory and fluency tests, both phonological and semantic [27, 30]. Several studies indicate sexual differences in processes of working memory [31]. In addition to working memory test results, male advantage in the Stocking of Cambridge [32] test has been reported, suggesting sex differences in the planning component of executive function [33]. Several studies have shown faster psychomotor speed in men [34] and poorer attention and psychomotor performance in women [35].

As brain tissue and neurons are neurobiological substrates for cognitive processes, it is unsurprising that healthy population has sexually dimorphic brain in morphology and physiology. The nature of this difference is unclear [36-38]. Differences between male and female gray matter concentration [39] or cortical thickness [40] as well as callosal thickness [41] were described. Male brain is of a larger volume (109-112\% of female brain); males have a greater volume of cerebrospinal fluid [42]. The total percentage of grey matter has been found to be smaller in men, and cortical gyrification and cortical complexity have been higher in women [43]. Sex differences include larger amygdala and hypothalamus in men and larger caudate and hippocampus in women $[44,45]$. Positron emission tomography (PET) and SPECT (single photon emission computed tomography) have revealed sexdependent differences in the central dopaminergic, serotonergic, and gamma-aminobutyric acid (GABA) ergic function [45]. Enhanced dopaminergic function in women has been reported [45], and dopamine is involved in prefrontal or executive tasks as many dopamine receptors are located in the frontal areas of the brain [46].

Although cognitive abnormalities are a well established feature of $\mathrm{BD}$, and the sexual dimorphism of the healthy brain is well known, there is limited information regarding whether gender may influence the pattern and severity of cognitive impairment in BD. Only a few studies have directly addressed the issue of gender differences in cognition of bipolar patients $[47,48]$.
1.1. Objective. The objective of the present study was to assess the performance of lithium treated euthymic bipolar patients in tests measuring spatial working memory and planning as well as verbal fluency and to delineate the influence of gender on the cognitive functioning of patients.

\section{Methods}

Fifty-nine patients (24 male, 35 female), aged 26-75 yr (mean \pm S.D.: $52 \pm 10 \mathrm{yr}$ ) with bipolar disorder attending the outpatient lithium clinic at the Department of Psychiatry, Poznan University of Medical Sciences, were studied. A consensus diagnosis by two psychiatrists was made for each patient, according to the DSM-IV criteria (structured clinical interview for DSM-IV Axis I-SCID) [49].

The patients were treated with lithium carbonate for at least $5 \mathrm{yr}(5-27 \mathrm{yr}$, mean $13 \mathrm{yr})$. Serum concentration of lithium was maintained in the range between 0.5 and $0.8 \mathrm{mmol} / \mathrm{L}$. The course of the illness was assessed retrospectively, based on the analysis of medical outpatient charts, in inpatient records, and semistructured interviews. The patients had variable numbers of episodes during lithium therapy (0-30, mean $5 \pm 6)$. Among patients, 13 were excellent lithium responders, defined as having had no affective episodes while on lithium monotherapy for the entire period of lithium administration [50]. The proportion of the excellent lithium responders in male and female groups did not differ significantly.

On the day of study, all patients were euthymic, as defined by a score of $<7$ on the 17 -item Hamilton Depression Rating Scale (HAMD17) [51] and a score of $<7$ on the Young Mania Rating Scale (YMRS) [52]. Fifty-nine healthy controls without personal or family history of mental illness recruited from the local community were matched head-to-head by age, gender, and education level. The study was approved by the Ethics Committee of Poznan University of Medical Sciences. Patients and volunteers gave their written informed consent after hearing a complete description of the study.

The exclusion criteria for both groups included dementia symptoms, a history of head trauma with loss of consciousness, substance abuse, epilepsy, and severe somatic illnesses.

Patients and controls underwent an extensive neuropsychological assessment. Several "paper-and-pencil" tests, The Trail Making Test (TMT) [53] and Verbal Fluency Test [54] as well as selected tests from the Cambridge Automated Neuropsychological Test Battery (CANTAB; CeNeS Ltd., Cambridge, UK) - Spatial Working Memory (SWM), spatial span (SSP), and Stocking of Cambridge [55-58]-were employed.

The tests were described in detail in our previous paper [14]. The Trail Making Test (TMT) consists of two parts. TMT requires subjects to connect 25 consecutively numbered circles (part A) and 25 numbered and lettered circles by shifting between the two sets (part B) as quickly as possible; the test is very sensitive to cerebral dysfunction. Part A of the test measures psychomotor speed; the results of part B reflect the ability to shift strategy and assess executive function and visuospatial working memory [59]. Time is recorded in seconds. 
TABLE 1: Sociodemographic and clinical characteristics (values expressed as means and standard deviations shown in brackets).

\begin{tabular}{|c|c|c|c|c|c|c|}
\hline & \multicolumn{3}{|c|}{ Patients group } & \multicolumn{3}{|c|}{ Control group } \\
\hline & $\begin{array}{c}\text { Overall } \\
(n=59) \\
\end{array}$ & $\begin{array}{c}\text { Males } \\
(n=24) \\
\end{array}$ & $\begin{array}{l}\text { Females } \\
(n=35) \\
\end{array}$ & $\begin{array}{c}\text { Overall } \\
(n=59) \\
\end{array}$ & $\begin{array}{c}\text { Males } \\
(n=24) \\
\end{array}$ & $\begin{array}{l}\text { Females } \\
(n=35) \\
\end{array}$ \\
\hline Age (years) & $52.4(10.2)$ & $50.0(10.0)$ & $53.9(10.2)$ & $52.7(11.7)$ & $48.5(10.6)$ & $55.6(11.6)^{a}$ \\
\hline Education (years) & $13.7(3.6)$ & $14.3(3.6)$ & $13.4(3.5)$ & $13.3(2.5)$ & $13.6(1.8)$ & $13.1(2.8)$ \\
\hline Age at illness onset (years) & $30.1(10.8)$ & $28.4(10.4)$ & $31.7(11.1)$ & - & - & - \\
\hline Number of episodes & $13.3(8.2)$ & $13.3(8.7)$ & $13.2(7.8)$ & - & - & - \\
\hline Duration of illness (years) & $21.8(10.7)$ & $21.4(10.6)$ & $22.2(11.0)$ & - & - & - \\
\hline Duration of lithium treatment (years) & $12.3(8.5)$ & $11.8(7.4)$ & $12.6(9.4)$ & - & - & - \\
\hline HDRS & $2.5(1.8)$ & $2.5(1.7)$ & $2.6(2.1)$ & $0.7(1.1)^{b}$ & $0.3(0.5)$ & $1(1.4)$ \\
\hline YMRS & $0.6(0.9)$ & $0.7(1.0)$ & $0.3(0.7)$ & $0.4(0.7)$ & $0.3(0.8)$ & $0.4(0.7)$ \\
\hline
\end{tabular}

YMRS: Young Mania Rating Scale; HDRS: Hamilton Depression Rating Scale.

${ }^{\text {a }} P<0.05$ : difference between male controls and female controls.

${ }^{\mathrm{b}} P<0.01$ : difference between patients and control group.

Verbal Fluency Tests. Phonologic verbal fluency was studied by asking subjects to generate as many words as possible that begin with each of the letters $\mathrm{F}, \mathrm{A}$, and $\mathrm{S}$, in consecutive 1 min time periods (FAS Test, from the COWAT: Controlled Oral Word Association Test) [60]. Semantic verbal fluency was measured with the Category Instant Generation Test, by naming as many items as possible in a given category (animals, vegetables, and fruit) within the same time limit. Scores were the sum of all acceptable words produced in the three trials. Verbal fluency is a sensitive measure of executive functions, as it requires the subject to generate their own strategy [61].

Spatial Working Memory (SWM). It is a test of the subject's ability to retain spatial information and to manipulate the remembered items in the working memory. The test measures the working memory for spatial stimuli and requires the subject to use mnemonic information to work towards a goal. Subjects are required to search through boxes that appear on the screen with the aim of finding the "blue tokens" hidden inside. The outcome measures for SWM include errors and strategy; higher strategy scores represent lower use of a strategy. This test is used to detect frontal lobe and executive dysfunction.

Spatial Span (SSP). A visuospatial analogue of the Digit Span test assesses working memory capacity. The Spatial Span is calculated at the highest level at which the subject successfully remembers at least one sequence of boxes.

CANTAB Stockings of Cambridge Planning Task [32]. This is a visuospatial planning test based on the Tower of London task [62]. The participant uses the balls in the lower display to copy the pattern shown in the upper display. It is the test of spatial planning ability and a measure of frontal lobe function [33]. Screenshots and detailed overviews of the tests are available online [63].

\section{Statistics and Results}

Statistical analyses were carried out with Statistica version 10.0 for Windows. To evaluate the normality of distribution of the variables, the Shapiro-Wilk test was applied. As most of the investigated variables were not normally distributed, nonparametric tests were employed. Between-group differences in the demographic characteristics and neuropsychological tests were assessed by the Mann-Whitney test. All the results were expressed as the mean and standard deviation (S.D.). Statistical significance was set at $P<0.05$ for all analyses.

Patients and controls were well matched for sex, age, and level of education. Patients' HDRS score $(2.5 \pm 1.8)$ was low but it was higher than controls $(0.7 \pm 1.1)$ with $P<0.01$. No differences between controls and patients in the YMRS scale were present. There were no significant differences between female patients and male patients as regards the age of illness onset, duration of illness, number of phases, or the duration of lithium treatment. Male and female patients had no significant differences regarding HDRS scores or YMRS scores on the day of the study. Male controls were younger than female controls $(P<0.05)$ (Table 1$)$.

Bipolar patients had significantly worse results than the healthy controls (Table 2) on the Spatial Span, Spatial Working Memory, Stockings of Cambridge, Trail Making Test, and verbal fluency tests. As far as the SWM strategy scores and SWM between errors scores are concerned, the diagnostic group performed worse; however no statistical difference was detected as regards the SWM within errors score. The number of errors in SSP did not differ between the groups.

Gender effect (Tables 3, 4, and 5). In the bipolar group, the results of women and men were almost identical. Bipolar male patients performed worse on the semantic fluency test $(P<0.05)$ but scored better on the SOC problems solved in minimum moves $(P<0.01)$, which assesses planning 
TABLE 2: Group differences in cognitive performance (values expressed as means and standard deviations shown in brackets).

\begin{tabular}{|c|c|c|c|}
\hline Test & Patients & Controls & Statistics \\
\hline SSP span length & $4.9(1.1)$ & $5.4(1.1)$ & $P<0.01$ \\
\hline SSP total errors & $12.6(5.2)$ & $12.1(5.3)$ & NS \\
\hline SWM strategy & $37.3(4.3)$ & $34.9(5.1)$ & $P<0.05$ \\
\hline SWM within errors & $4.8(5.4)$ & $3.4(4.2)$ & NS \\
\hline SWM between errors & $46.5(19.8)$ & $35.1(19.8)$ & $P<0.01$ \\
\hline SOC mean initial thinking time (5 moves) & $11497.6(11.849 .0)$ & $8816.8(5717.0)$ & $P<0.01$ \\
\hline SOC mean subsequent thinking time (5 moves) & $3636.1(2472.2)$ & $3270.0(3323.9)$ & NS \\
\hline SOC problems solved in minimum moves & $7.6(1.6)$ & $7.5(1.7)$ & NS \\
\hline Semantic fluency (number of words) & $41.2(8.6)$ & $49.1(8.9)$ & $P<0.001$ \\
\hline Phonemic fluency (number of words) & $28.7(8.7)$ & $36.4(14.6)$ & $P<0.01$ \\
\hline TMT A (time (sec)) & $44.4(17.5)$ & $34.9(10)$ & $P<0.01$ \\
\hline TMT B (time (sec)) & $113.9(46.8)$ & $81.9(43.6)$ & $P<0.001$ \\
\hline
\end{tabular}

TABLE 3: Within-group comparisons of cognitive functions (values expressed as means and standard deviations shown in brackets).

\begin{tabular}{|c|c|c|c|c|c|c|}
\hline & \multicolumn{3}{|c|}{ Controls } & \multicolumn{3}{|c|}{ Patients } \\
\hline & Males & Females & $P$ & Males & Females & $P$ \\
\hline SSP span length & $5.6(1.3)$ & $5.4(1.0)$ & NS & $5.0(1.3)$ & $4.9(0.9)$ & NS \\
\hline SSP total errors & $12.0(6.2)$ & $12.1(4.7)$ & NS & $14.4(6.9)$ & $11.7(4.1)$ & NS \\
\hline SWM strategy & $33.4(5.8)$ & $35.9(4.4)$ & $P<0.05$ & 37. $0(5.6)$ & $37.5(3.3)$ & NS \\
\hline SWM within errors & $2.6(4.3)$ & $4.1(4.1)$ & $P<0.05$ & $6.7(7.9)$ & $3.6(2.74)$ & NS \\
\hline SWM between errors & $28.4(19.7)$ & $39.8(18.8)$ & $P<0.05$ & $45.8(18.7)$ & $47.0(20.7)$ & NS \\
\hline $\begin{array}{l}\text { SOC mean initial thinking time ( } 5 \\
\text { moves) }\end{array}$ & $7969.6(6475.0)$ & $6059.2(5116.2)$ & NS & $9248.9(5951.1)$ & $13039.6(14475.1)$ & NS \\
\hline $\begin{array}{l}\text { SOC mean subsequent thinking time } \\
\text { ( } 5 \text { moves) }\end{array}$ & $2308.5(2168.9)$ & $3901.9(3800.2)$ & NS & $2935.7(2152.5)$ & $4116.3(2590.0)$ & NS \\
\hline $\begin{array}{l}\text { SOC problems solved in minimum } \\
\text { moves }\end{array}$ & $7.7(1.48)$ & $7.4(1.8)$ & NS & $8.3(1.5)$ & $7.1(1.5)$ & $P<0.01$ \\
\hline Semantic fluency (number of words) & $49.2(9.7)$ & $49.1(8.4)$ & NS & $37.6(5.8)$ & $43.2(9.3)$ & $P<0.05$ \\
\hline Phonemic fluency (number of words) & $37.5(12.9)$ & $35.7(15.8)$ & NS & $26.9(8.3)$ & $29.7(8.9)$ & NS \\
\hline TMT A (time (sec)) & $30.9(7.1)$ & $37.3(10.7)$ & $P<0.05$ & $43.1(17.8)$ & $45.1(17.5)$ & NS \\
\hline TMT B (time (sec)) & $71.6(16.9)$ & $88.0(52.9)$ & NS & $115.7(46.6)$ & $112.9(47.6)$ & NS \\
\hline
\end{tabular}

ability. In the control group, male individuals scored significantly better on TMT A, made significantly less betweensearch errors in SWM $(P<0.05)$, and tended to have a better strategy in SWM than female controls $(P=0.6)$. No more differences between the healthy subjects were found. We detected a gender-related imbalance in the SWM results. Deficits in SWM were observed in male-only comparisons (both in the Strategy and Between-errors scores) but not in female-only comparisons. The SWM Strategy scores were significantly poorer in male patients than in male controls $(P<$ $0.05)$. Male patients also made significantly more betweensearch errors $(P<0.01)$. In the SWM within errors scores a trend towards worse results in bipolar men was detected as well ( $P=0.09)$. In female-only comparisons, female patients did not have significantly poorer SWM results in any category (strategy scores, between-search errors, and within errors) than their controls. Bipolar women scored worse in SSP length, SOC mean initial thinking time, TMT-both parts, and the semantic fluency test.

\section{Discussion}

Over the last decade, a growing body of evidence has shown the persistence of cognitive deficits during all phases of bipolar disorder, including the affective states and the remission (euthymia) [17, 23]. Euthymic BD patients have been found to suffer from marked impairment across the cognitive domains of attention/processing speed, verbal learning/memory, and executive functioning in many studies $[64,65]$.

The results of our study point to the deficits in visuospatial abilities in the group of euthymic bipolar patients. The Spatial Working Memory (SWM) test assesses subject's ability to retain and manipulate spatial information. Bipolar patients in our study made more between-search errors and had poorer strategy scores in that test. Similar results of spatial and verbal memory impairments in $\mathrm{BD}$ have been reported by Yatham et al. [65] but not by Pirkola et al. [25]. The capacity of visuospatial working memory was worse in the patients than in the healthy controls as the Spatial Span length was 
TABLE 4: Male-only and female-only comparisons of cognitive functions (values expressed as means and standard deviations shown in brackets).

\begin{tabular}{|c|c|c|c|c|c|c|}
\hline & & Males & & & Females & \\
\hline & Patients & Controls & $P$ & Patients & Controls & $P$ \\
\hline SSP span length & $5.0(1.3)$ & $5.6(1.3)$ & NS & $4.9(0.9)$ & $5.4(1.0)$ & $P<0.05$ \\
\hline SSP total errors & $14.4(6.9)$ & $12.0(6.2)$ & NS & $11.7(4.1)$ & $12.1(4.7)$ & NS \\
\hline SWM strategy & $37.0(5.6)$ & $33.5(5.8)$ & $P<0.05$ & $37.5(3.3)$ & $36.0(4.4)$ & NS \\
\hline SWM within errors & $6.7(8.0)$ & $2.6(4.3)$ & NS & $3.6(2.7)$ & $4.1(4.1)$ & NS \\
\hline SWM between errors & $45.8(18.7)$ & $28.5(19.7)$ & $P<0.01$ & $47.0(20.7)$ & $39.8(18.8)$ & NS \\
\hline $\begin{array}{l}\text { SOC mean initial thinking time ( } 5 \\
\text { moves) }\end{array}$ & $9248.9(5951.1)$ & $7969.6(6475.0)$ & NS & $13039.6(14475.1)$ & $6059.2(5116.2)$ & $P<0.01$ \\
\hline $\begin{array}{l}\text { SOC mean subsequent thinking time } \\
\text { ( } 5 \text { moves) }\end{array}$ & $2935.7(2152.5)$ & $2308.5(2168.9)$ & NS & $4116.3(2590.0)$ & $3901.9(3800.2)$ & NS \\
\hline $\begin{array}{l}\text { SOC problems solved in minimum } \\
\text { moves }\end{array}$ & $8.3(1.5)$ & $7.7(1.5)$ & NS & $7.1(1.5)$ & $7.4(1.8)$ & NS \\
\hline Semantic fluency (number of words) & $37.6(5.8)$ & $49.2(9.7)$ & $P<0.001$ & $43.2(9.3)$ & $49.1(8.4)$ & $P<0.01$ \\
\hline $\begin{array}{l}\text { Phonemic fluency (number of words) } \\
P<0.004\end{array}$ & $26.9(8.3)$ & $37.5(12.9)$ & $P<0.01$ & $29.7(8.9)$ & $35.7(15.8)$ & NS \\
\hline TMT A (time (sec)) & $43.1(17.8)$ & $30.9(7.2)$ & $P<0.05$ & $45.1(17.5)$ & $37.3(10.7)$ & $P<0.05$ \\
\hline TMT B (time (sec)) & $115.7(46.6)$ & $71.6(16.9)$ & $P<0.001$ & $112.9(47.6)$ & $88.0(52.9)$ & $P<0.01$ \\
\hline
\end{tabular}

significantly shorter in the diagnostic group. Visuospatial planning was assessed using the SOC test. The results of SOC subsequent thinking time and SOC problems solved in minimum moves did not differ between the groups whilst the mean initial thinking time of the SOC test was significantly longer in the patients' group. Worse results in the TMT part $B$ also showed deficits in executive functions and visuospatial working memory in bipolar patients. TMT has been recently described as a robust measure of cognitive impairments in bipolar disorder patients [13].

These findings coincide with the existing literature, as specific deficits in working memory and executive control have been identified in euthymic bipolar patients [17, 66, 67].

Moreover, our patients also had worse results in the FAS test reflecting the impaired executive function, which are consistent with the results of BD samples in metaanalysis by Kurtz and Gerraty [23].

The precise etiology and pathophysiology of cognitive impairment in BD have not been fully elucidated. During working memory tasks dorsolateral prefrontal cortex (DLPFC), inferior prefrontal cortex, areas of the parietal lobe, and the anterior cingulate cortex are involved $[68,69]$. There is a growing body of evidence implying that the ventral frontopolar dysfunction is a core abnormality in $\mathrm{BD}$ [70]. Impairments of spatial working memory in schizophrenic patients were well described and imply the frontal-striatalparietal (particularly prefrontal cortex) neural networks dysfunction [71].

In our patients' group, the deficits of visuospatial memory in SWM were more prominent in male patients. Whereas the results of visuospatial tests of healthy men were significantly better than those of control women on SWM between errors and they tended to be better on the SWM strategy, no such difference was observed between male and female BD patients in the within-patients comparison.

Gender-related disequilibrium in SWM reported in healthy individuals [23] was absent in our bipolar patients. In bipolar male patients, no correlation between the SWM results and clinical factors was observed. Female patients' SWM results correlated with the duration of illness, and such a correlation suggests that some impairments may track illness progression [13].

According to Barrett's hypothesis, this suggests that the impact of BD on SWM is different depending on patients' gender [72]. The authors [72] have compared the results of 12 male and 14 female BD outpatients with those of healthy controls on letter fluency, spatial working memory, planning, and cognitive set shifting. Male patients have performed worse than female patients in measures of spatial working memory, indicative of poor retention of the visuospatial information. However, male patients in that study had been both older and more symptomatic than female patients.

Carrus et al. [47] have evaluated the performance of 86 remitted patients with $\mathrm{BD}$ type I (36 male and 50 female) and 46 healthy participants ( 21 male and 25 female) on tasks of general intellectual ability, memory encoding, recognition and retrieval, response inhibition, and executive function (abstraction and perseveration). They have found a gender effect and an interaction between diagnosis and gender on immediate memory, both auditory and visual, but not on general intellectual ability, concept formation, and perseveration or response inhibition. Male patients have performed worse compared with female patients and healthy controls. Immediate memory has correlated with GAF scores and this association has been statistically significant for male patients [47]. 
TABLE 5: Correlations between clinical factors and cognitive tests results ( ${ }^{*}$ significant at $\left.P<0.05\right)$ in bipolar patients.

\begin{tabular}{|c|c|c|c|c|c|c|}
\hline & & Age at onset & $\begin{array}{l}\text { Number of } \\
\text { episodes }\end{array}$ & Illness duration & YMRS & HDRS \\
\hline \multirow{3}{*}{ SSP span length } & $\mathrm{O}$ & 0.01 & $-0.44^{*}$ & $-0.29^{*}$ & 0.01 & -0.19 \\
\hline & $\mathrm{M}$ & 0.01 & -0.40 & -0.12 & -0.01 & -0.24 \\
\hline & $\mathrm{F}$ & 0.04 & $-0.51^{*}$ & $-0.49^{*}$ & 0.18 & -0.08 \\
\hline \multirow{3}{*}{ SWM strategy } & $\mathrm{O}$ & -0.09 & 0.20 & 0.25 & 0.16 & 0.14 \\
\hline & M & -0.00 & 0.15 & 0.05 & 0.25 & -0.06 \\
\hline & $\mathrm{F}$ & -0.26 & 0.28 & $0.48^{*}$ & 0.04 & 0.46 \\
\hline \multirow{3}{*}{ SWM between errors } & $\mathrm{O}$ & -0.00 & 0.24 & $0.35^{*}$ & 0.02 & -0.18 \\
\hline & $\mathrm{M}$ & -0.02 & 0.16 & 0.02 & 0.12 & -0.12 \\
\hline & $\mathrm{F}$ & -0.04 & 0.31 & $0.58^{*}$ & -0.15 & -0.26 \\
\hline \multirow{3}{*}{$\begin{array}{l}\text { SOC mean initial thinking time } \\
(5 \text { moves) }\end{array}$} & $\mathrm{O}$ & 0.23 & 0.21 & -0.19 & 0.32 & $0.42^{*}$ \\
\hline & $\mathrm{M}$ & -0.31 & $0.58^{*}$ & $0.48^{*}$ & 0.22 & 0.32 \\
\hline & $\mathrm{F}$ & $0.43^{*}$ & 0.08 & $-0.46^{*}$ & $0.93^{*}$ & 0.60 \\
\hline \multirow{3}{*}{$\begin{array}{l}\text { SOC mean subsequent thinking } \\
\text { time ( } 5 \text { moves) }\end{array}$} & $\mathrm{O}$ & 0.17 & -0.00 & -0.05 & 0.25 & -0.18 \\
\hline & $\mathrm{M}$ & 0.04 & 0.32 & -0.01 & 0.37 & -0.14 \\
\hline & $\mathrm{F}$ & 0.19 & -0.23 & -0.10 & 0.24 & -0.35 \\
\hline \multirow{3}{*}{$\begin{array}{l}\text { SOC problems solved in } \\
\text { minimum moves }\end{array}$} & $\mathrm{O}$ & $0.33^{*}$ & $-0.28^{*}$ & -0.16 & 0.24 & 0.12 \\
\hline & M & 0.36 & $-0.50^{*}$ & -0.15 & 0.19 & 0.11 \\
\hline & $\mathrm{F}$ & $0.46^{*}$ & -0.11 & -0.17 & 0.32 & 0.27 \\
\hline \multirow{3}{*}{ Semantic fluency } & $\mathrm{O}$ & -0.14 & -0.05 & -0.18 & -0.13 & 0.21 \\
\hline & $\mathrm{M}$ & -0.45 & 0.02 & -0.03 & -0.03 & 0.18 \\
\hline & $\mathrm{F}$ & -0.06 & -0.07 & -0.28 & -0.12 & 0.34 \\
\hline \multirow{3}{*}{ Phonemic fluency } & $\mathrm{O}$ & -0.03 & -0.27 & -0.26 & 0.09 & 0.06 \\
\hline & $\mathrm{M}$ & -0.13 & -0.19 & 0.02 & 0.09 & -0.09 \\
\hline & $\mathrm{F}$ & 0.01 & -0.31 & $-0.43^{*}$ & 0.32 & 0.52 \\
\hline \multirow{3}{*}{ TMT A } & $\mathrm{O}$ & 0.25 & 0.07 & 0.16 & 0.05 & -0.18 \\
\hline & M & 0.37 & 0.30 & 0.03 & 0.26 & 0.11 \\
\hline & $\mathrm{F}$ & 0.15 & -0.10 & 0.24 & $-0.68^{*}$ & $-0.80^{*}$ \\
\hline \multirow{3}{*}{ TMT B } & $\mathrm{O}$ & 0.20 & 0.21 & 0.05 & 0.20 & -0.21 \\
\hline & $\mathrm{M}$ & 0.30 & 0.11 & -0.37 & 0.35 & -0.02 \\
\hline & $\mathrm{F}$ & 0.14 & 0.27 & 0.26 & -0.28 & -0.53 \\
\hline
\end{tabular}

O: overall group of bipolar patients.

M: male patients.

F: female patients.

YMRS: Young Mania Rating Scale.

HDRS: Hamilton Depression Rating Scale.

In another study, a group of 106 BD I patients (55 women/ 51 men) has been assessed with an extensive neuropsychological test battery and the social functioning questionnaire and compared with the control group and schizophrenic patients group [73]. Clinical groups have performed worse than healthy controls for all neuropsychological tests (except attention). The authors have found neurocognitive sex differences for bipolar disorder but their data have not supported the hypothesis of disruption of normal sexual dimorphisms in BD patients, which has been reported for schizophrenic patients. In terms of cognitive results, there has been no general "different sex difference" between bipolar disorder patients compared with healthy controls. According to
Vaskinn et al. [73] the neurocognitive sex differences found in their study could depend on the normal sexual dimorphisms in brain structures seen in healthy populations.

Greater impairment in working memory including spatial memory has been observed in bipolar patients with a history of psychosis in comparison with the remaining bipolar patients [74].

The results of the study of cognitive functions of 60 euthymic patients who had recently experienced their first manic or mixed episode [48] have been consistent with those of Vaskinn et al. [73] but somewhat disagreed with the results of Barrett et al. [72] and Carrus et al. [47]. Popuri [48] has found that bipolar patients as a group showing a poorer 
cognitive performance than age- and sex-matched healthy controls. Sex has been an important determinant of the neurocognitive function: males performed better than females on measures of sustained attention and set shifting, whereas females have tended to perform better than males in verbal learning. There have been no group and sex interactions indicating that sex has the same impact on the neurocognitive function in bipolar I patients as in healthy controls. Data concerning gender differences in brain morphology are also sparse [70]. Mackay et al. [75] have reported that the normal sex difference in brain asymmetry tends to be diminished in patients with bipolar disorder. Bipolar disorder has been characterized by an increased cerebrospinal fluid volume, and although there has been no overall change in brain volume, male patients had increased and female patients decreased lobe volumes relative to sex-matched controls. Considered as a neurodevelopmental illness, bipolar disorder may represent a sex-dependent anomaly in the growth of the cerebral cortex [75]. In the review of neuroimaging findings in $\mathrm{BD}$ patients, Jogia et al. [70] suggest that the sex of an individual modulates the structure and function within the subcortical and cortical regions implicated in the disease expression. The influence of sex on structural brain morphology may probably be greater during the development than later in life, and it is unknown how prescribed medicines may influence both the morphology and functioning of brain. Persistent cognitive deficits have a number of clinical implications for $\mathrm{BD}$ patients. Intact cognitive functioning is critical for success in independent, useful functioning in everyday life [54]. Impaired executive functions have been found to relate to poor outcome and problematical management in brain injury [76] and poor psychosocial and occupational functioning in $\mathrm{BD}$ patients [77]. In this way, gender might be a factor associated with poorer social outcome in BD [6]. One of the most important aims of future research should therefore be the identification of the underlying neurobiology of neurocognitive impairment in euthymic patients, thereby, providing a target for therapeutic intervention.

Many studies have shown that BD patients have cognitive executive-type dysfunctions $[67,77,78]$ which may potentially serve as endophenotypes for $\mathrm{BD}$. As many authors underline, affective symptoms (clinical phenotype) can probably contribute less to the knowledge of the underlying pathology of $\mathrm{BD}$ than neurocognitive deficits [79]. Metaanalyses and critical literature reviews [18, 19, 21, 23] based on numerous studies suggest that cognitive performance is something like cover measures for BD traits, that is, measures between the underlying genetic contribution and easily seen symptoms [79]. The metaanalysis of neuropsychological functioning in euthymic bipolar disorder conducted by Mann-Wrobel et al. [17] has concluded that cognitive impairments in euthymic bipolar disorders are rather generalized than specific. On the other hand, age, illness duration, education, and clinical course may moderate these broad cognitive effects. The direction of impact is unknown; causality cannot be determined from correlation analyses; [66] patients with cognitive impairment may develop a more severe type and course of $\mathrm{BD}$, and a severe $\mathrm{BD}$ course leads to a greater impairment in cognitive functions and, consequently, a poorer functional outcome.

Cognitive and psychoeducational rehabilitation programs may be warranted to improve the long-term outcome for some patients [66]. They should be adjusted to the individual needs, and patients' gender has to be taken into account in terms of different gender-related cognitive impairment.

We are aware of the limitations of this study, including a possible impact of medications. A comparison between our results and those of other studies is biased by different inclusion criteria, and different stage of illness, treatment methods, and differences in somatic comorbidity (and comedication) [20]. All our patients were on prophylactic lithium treatment (mean $12.3 \mathrm{yr}$ ) just like those referred to in Barrett's paper [72]. Lithium has been used for over 50 years as a recognized medication for the treatment of both mania and depression, and the maintenance of well-being in bipolar disorder [3]. Lithium is an efficacious agent for the treatment of bipolar disorder, but it is unclear to what extent its long-term use may result in neuroprotective or neurotoxic consequences [80]. In the last two decades, a growing body of evidence has shown that lithium has several neuroprotective effects [81]. Neuroimaging studies in humans have demonstrated that chronic use is associated with cortical thickening, higher volume of the hippocampus and amygdala, and neuronal viability in bipolar patients on lithium treatment. Chronic lithium intake is associated with a reduced risk of Alzheimer's disease in subjects with bipolar disorder [81]. On the other hand, lithium has been reported to be associated with impairments in learning, memory, and psychomotor performance [82], but this association may be mediated by other factors, such as other medications or symptoms of the affective phase [26]. The authors of another review [83] have concluded that lithium carbonate has only mild negative effects on immediate verbal learning and memory and creativity and a moderate adverse effect on psychomotor performance in euthymic patients with affective disorders. Based on the review of literature, Fountoulakis et al. [80] have concluded that although more papers are in favour of the toxic effect, the great difference in the type of papers that support either hypothesis, along with publication bias and methodological issues, makes conclusions difficult.

\section{Conclusion}

The results of our study point to the presence of cognitive deficits in euthymic bipolar patients; therefore they support the statement of Bowden and Singh [84] pointing to the difference between remission and response and between syndromal recovery (amelioration of clinical symptoms) and functional recovery. Our results substantiate the postulation of Goodwin et al. [85] that neurocognitive impairment should be considered as a potential therapeutic target, to improve cognitive functions and the functional outcome of bipolar patients. Even though further studies are needed to clarify the relationship between gender and cognitive functions in bipolar disorder, the present study points to the different patterns of neuropsychological disturbances in 
female and male patients and suggests that sex-dependent differences should be taken into account in order to tailor the therapeutic intervention aimed at the improvement of cognitive functions.

\section{Conflict of Interests}

Dr. Suwalska and Dr. Łojko do not have any affiliation or financial interest in any organization that might imply a conflict of interests with the present paper.

\section{Acknowledgments}

This project was supported by funding from the National Science Centre Grant no. NN 402407 539, Kraków, Poland. The authors wish to thank Professor J. K. Rybakowski for conceptual advice, J. Janik and H. Cyranik for technical assistance, and Dr. W. Pałys for assistance with data collection.

\section{References}

[1] B. Dell'Osso, M. Buoli, R. Riundi et al., "Clinical characteristics and long-term response to mood stabilizers in patients with bipolar disorder and different age at onset," Neuropsychiatric Disease and Treatment, vol. 5, no. 1, pp. 399-404, 2009.

[2] K. R. Merikangas, H. S. Akiskal, J. Angst et al., "Lifetime and 12month prevalence of bipolar spectrum disorder in the national comorbidity survey replication," Archives of General Psychiatry, vol. 64, no. 5, pp. 543-552, 2007.

[3] A. Young, "Progress in the treatment of bipolar disorder," Neuropsychiatric Disease and Treatment, vol. 2, no. 2, pp. 119120, 2006

[4] V. Balanzá-Martínez, G. Selva, A. Martínez-Arán et al., "Neurocognition in bipolar disorders-a closer look at comorbidities and medications," European Journal of Pharmacology, vol. 626, no. 1, pp. 87-96, 2010.

[5] V. Hendrick, L. L. Altshuler, M. J. Gitlin, S. Delrahim, and C. Hammen, "Gender and bipolar illness," Journal of Clinical Psychiatry, vol. 61, no. 5, pp. 393-396, 2000.

[6] A. Diflorio and I. Jones, "Is sex important gender differences in bipolar disorder," International Review of Psychiatry, vol. 22, no. 5, pp. 437-452, 2010.

[7] P. Vega, S. Barbeito, S. R. de Azúa et al., "Bipolar disorder differences between genders: special considerations for women," Women's Health, vol. 7, no. 6, pp. 663-676, 2011.

[8] N. Rasgon, M. Bauer, P. Grof et al., "Sex-specific self-reported mood changes by patients with bipolar disorder," Journal of Psychiatric Research, vol. 39, no. 1, pp. 77-83, 2005.

[9] I. Kawa, J. D. Carter, P. R. Joyce et al., "Gender differences in bipolar disorder: age of onset, course, comorbidity, and symptom presentation," Bipolar Disorders, vol. 7, no. 2, pp. 119125, 2005.

[10] K. Suominen, O. Mantere, H. Valtonen, P. Arvilommi, S. Leppämäki, and E. Isometsä, "Gender differences in bipolar disorder type I and II," Acta Psychiatrica Scandinavica, vol. 120, no. 6, pp. 464-473, 2009.

[11] E. Leclerc, R. B. Mansur, and E. Brietzke, "Determinants of adherence to treatment in bipolar disorder: a comprehensive review," Journal of Affective Disorder, vol. 49, no. 1-3, pp. 247252, 2013.
[12] A. M. A. Nivoli, I. Pacchiarotti, A. R. Rosa et al., "Gender differences in a cohort study of 604 bipolar patients: the role of predominant polarity," Journal of Affective Disorders, vol. 133, no. 3, pp. 443-449, 2011.

[13] C. Bourne, O. Aydemir, V. Balanza-Martinez et al., "Neuropsychological testing of cognitive impairment in euthymic bipolar disorder: an individual patient data meta-analysis," Acta Psychiatrica Scandinavia, vol. 128, no. 3, pp. 149-162, 2013.

[14] A. Suwalska and D. Łojko, "Cognitive functions in euthymic bipolar patients and lithium," in Mood Disorders, N. Kocabasoglu, Ed., InTech, Istanbul, Turkey, 2013.

[15] J. F. Goldberg and K. N. R. Chengappa, "Identifying and treating cognitive impairment in bipolar disorder," Bipolar Disorders, vol. 11, supplement 2, pp. 123-137, 2009.

[16] A. Martínez-Arán, E. Vieta, M. Reinares et al., "Cognitive function across manic or hypomanic, depressed, and euthymic states in bipolar disorder," The American Journal of Psychiatry, vol. 161, no. 2, pp. 262-270, 2004.

[17] M. C. Mann-Wrobel, J. T. Carreno, and D. Dickinson, "Metaanalysis of neuropsychological functioning in euthymic bipolar disorder: an update and investigation of moderator variables," Bipolar Disorders, vol. 13, no. 4, pp. 334-342, 2011.

[18] L. J. Robinson, J. M. Thompson, P. Gallagher et al., "A metaanalysis of cognitive deficits in euthymic patients with bipolar disorder," Journal of Affective Disorders, vol. 93, no. 1-3, pp. 105$115,2006$.

[19] I. J. Torres, V. G. Boudreau, and L. N. Yatham, "Neuropsychological functioning in euthymic bipolar disorder: a metaanalysis," Acta Psychiatrica Scandinavica, vol. 116, no. 434, pp. 17-26, 2007.

[20] B. Arts, N. Jabben, L. Krabbendam, and J. van Os, "Metaanalyses of cognitive functioning in euthymic bipolar patients and their first-degree relatives," Psychological Medicine, vol. 38, no. 6, pp. 771-785, 2008.

[21] E. Bora, M. Yucel, and C. Pantelis, "Cognitive endophenotypes of bipolar disorder: a meta-analysis of neuropsychological deficits in euthymic patients and their first-degree relatives," Journal of Affective Disorders, vol. 113, no. 1-2, pp. 1-20, 2009.

[22] E. Stefanopoulou, A. Manoharan, S. Landau, J. R. Geddes, G. Goodwin, and S. Frangou, "Cognitive functioning in patients with affective disorders and schizophrenia: a meta-analysis," International Review of Psychiatry, vol. 21, no. 4, pp. 336-356, 2009.

[23] M. M. Kurtz and R. T. Gerraty, "A meta-analytic investigation of neurocognitive deficits in bipolar illness: profile and effects of clinical state," Neuropsychology, vol. 23, no. 5, pp. 551-562, 2009.

[24] L. V. Frantom, D. N. Allen, and C. L. Cross, "Neurocognitive endophenotypes for bipolar disorder," Bipolar Disorders, vol. 10, no. 3, pp. 387-399, 2008.

[25] T. Pirkola, A. Tuulio-Henriksson, D. Glahn et al., "Spatial working memory function in twins with schizophrenia and bipolar disorder," Biological Psychiatry, vol. 58, no. 12, pp. 930936, 2005.

[26] K. Latalova, J. Prasko, T. Diveky, and H. Velartova, "Cognitive impairment in bipolar disorder," Biomedical Papers, vol. 155, no. 1, pp. 19-26, 2011.

[27] J. M. Andreano and L. Cahill, "Sex influences on the neurobiology of learning and memory," Learning and Memory, vol. 16, no. 4, pp. 248-266, 2009.

[28] L. A. M. Galea and D. Kimura, "Sex differences in routelearning," Personality and Individual Differences, vol. 14, no. 1, pp. 53-65, 1993. 
[29] I. Silverman, J. Choi, and M. Peters, “The Hunter-gatherer theory of sex differences in spatial abilities: data from 40 countries," Archives of Sexual Behavior, vol. 36, no. 2, pp. 261-268, 2007.

[30] P. P. Thilers, S. W. S. MacDonald, and A. Herlitz, "Sex differences in cognition: the role of handedness," Physiology and Behavior, vol. 92, no. 1-2, pp. 105-109, 2007.

[31] O. Speck, T. Ernst, J. Braun, C. Koch, E. Miller, and L. Chang, "Gender differences in the functional organization of the brain for working memory," NeuroReport, vol. 11, no. 11, pp. 2581-2585, 2000.

[32] American Psychiatric Association, Diagnostic and Statistical Manual of Mental Disorders, APA, Washington, DC, USA, 4th edition, 2000.

[33] C. R. de Luca, S. J. Wood, V. Anderson et al., "Normative data from the Cantab. I: development of executive function over the lifespan," Journal of Clinical and Experimental Neuropsychology, vol. 25, no. 2, pp. 242-254, 2003.

[34] P. Era, P. Sainio, S. Koskinen, J. Ohlgren, T. Härkänen, and A. Aromaa, "Psychomotor speed in a random sample of 7979 subjects aged 30 years and over," Aging-Clinical and Experimental Research, vol. 23, no. 2, pp. 135-144, 2011.

[35] J. M. Mazaux, J. F. Dartigues, L. Letenneur et al., "Visuo-spatial attention and psychomotor performance in elderly community residents: effects of age, gender, and education," Journal of Clinical and Experimental Neuropsychology, vol. 17, no. 1, pp. 7181, 1995 .

[36] D. Kimura and P. G. Clarke, "Women's advantage on verbal memory is not restricted to concrete words," Psychological Reports, vol. 91, no. 3, pp. 1137-1142, 2002.

[37] D. Kimura and R. A. Harshman, "Sex differences in brain organization for verbal and non-verbal functions," Progress in Brain Research, vol. 61, pp. 423-441, 1984.

[38] D. W. Collins and D. Kimura, "A large sex difference on a twodimensional mental rotation task," Behavioral Neuroscience, vol. 111, no. 4, pp. 845-849, 1997.

[39] E. Luders, K. L. Narr, P. M. Thompson et al., "Mapping cortical gray matter in the young adult brain: effects of gender," NeuroImage, vol. 26, no. 2, pp. 493-501, 2005.

[40] E. Luders, K. L. Narr, P. M. Thompson et al., "Gender effects on cortical thickness and the influence of scaling," Human Brain Mapping, vol. 27, no. 4, pp. 314-324, 2006.

[41] E. Luders, K. L. Narr, E. Zaidel, P. M. Thompson, and A. W. Toga, "Gender effects on callosal thickness in scaled and unscaled space," NeuroReport, vol. 17, no. 11, pp. 1103-1106, 2006.

[42] S. F. Witelson, H. Beresh, and D. L. Kigar, "Intelligence and brain size in 100 postmortem brains: sex, lateralization and age factors," Brain, vol. 129, no. 2, pp. 386-398, 2006.

[43] E. Luders, C. Gaser, L. Jancke, and G. Schlaug, "A voxel-based approach to gray matter asymmetries," NeuroImage, vol. 22, no. 2, pp. 656-664, 2004.

[44] B. Crespo-Facorro, L. Barbadillo, J. M. Pelayo-Terán, and J. M. Rodríguez-Sánchez, "Neuropsychological functioning and brain structure in schizophrenia," International Review of Psychiatry, vol. 19, no. 4, pp. 325-336, 2007.

[45] K. P. Cosgrove, C. M. Mazure, and J. K. Staley, "Evolving knowledge of sex differences in brain structure, function, and chemistry," Biological Psychiatry, vol. 62, no. 8, pp. 847-855, 2007.

[46] T. W. Robbins, "Chemical neuromodulation of frontalexecutive functions in humans and other animals," Experimental Brain Research, vol. 133, no. 1, pp. 130-138, 2000.
[47] D. Carrus, T. Christodoulou, M. Hadjulis et al., "Gender differences in immediate memory in bipolar disorder," Psychological Medicine, vol. 40, no. 8, pp. 1349-1355, 2010.

[48] S. Popuri, Cognitive Functioning in Bipolar Disorder: Influence of Sex, The University of British Columbia, Vancouver, Canada, 2012.

[49] M. First, R. Spitzer, M. Gibbon et al., Structured Clinical Interview for DSM-IV Axis I Disorders, Research Version, Biometrics Research, New York, NY, USA, 1997.

[50] P. Grof, "Excellent lithium responders: people whose lives have been changed by lithium prophylaxis," in Lithium: 50 Years of Psychopharmacology: New Perspectives in Biomedical and Clinical Research, N. J. Birch, V. S. Gallicchio, and R. W. Becker, Eds., pp. 36-51, Weidner Publishing Group, Cheshire, Conn, USA, 1999.

[51] M. Hamilton, "A rating scale for depression," Journal of Neurology, Neurosurgery, and Psychiatry, vol. 23, pp. 56-62, 1960.

[52] R. C. Young, J. T. Biggs, V. E. Ziegler, and D. A. Meyer, "A rating scale for mania: reliability, validity and sensitivity," The British Journal of Psychiatry, vol. 133, no. 11, pp. 429-435, 1978.

[53] R. M. Reitan, "The relation of the trail making test to organic brain damage," Journal of Consulting Psychology, vol. 19, no. 5, pp. 393-394, 1955.

[54] M. D. Lezak, D. B. Howieson, and D. W. Loring, Neuropsychological Assessment, Oxford University Press, New York, NY, USA, 4th edition, 2004.

[55] R. Elliott, B. J. Sahakian, A. P. Mckay, J. J. Herrod, T. W. Robbins, and E. S. Paykel, "Neuropsychological impairments in unipolar depression: the influence of perceived failure on subsequent performance," Psychological Medicine, vol. 26, no. 5, pp. 975989, 1996.

[56] R. Purcell, P. Maruff, M. Kyrios, and C. Pantelis, "Neuropsychological function in young patients with unipolar major depression," Psychological Medicine, vol. 27, no. 6, pp. 1277-1285, 1997.

[57] L. Clark, S. D. Iversen, and G. M. Goodwin, "Sustained attention deficit in bipolar disorder," The British Journal of Psychiatry, vol. 180, pp. 313-319, 2002.

[58] A. M. Owen, J. Doyon, M. Petrides, and A. C. Evans, "Planning and spatial working memory: a positron emission tomography study in humans," European Journal of Neuroscience, vol. 8, no. 2, pp. 353-364, 1996.

[59] R. M. Reitan, "Validity of the trail making test as an indicator of organic brain damage," Perceptual and Motor Skills, vol. 8, pp. 271-276, 1958.

[60] J. G. Borkowski, A. L. Benton, and O. Spreen, "Word fluency and brain damage," Neuropsychologia, vol. 5, no. 2, pp. 135-140, 1967.

[61] M. Piskunowicz, M. Bieliński, A. Zgliński et al., "Verbal fluency tests-application in neuropsychological assessment," Psychiatria Polska, vol. 47, no. 3, pp. 475-485, 2013.

[62] T. Shallice, "Specific impairments of planning," Philosophical transactions of the Royal Society of London B, vol. 298, no. 1089, pp. 199-209, 1982.

[63] http://www.cantabeclipse.com/cantab-tests.asp.

[64] P. D. Harvey, A. P. Wingo, K. E. Burdick, and R. J. Baldessarini, "Cognition and disability in bipolar disorder: lessons from schizophrenia research," Bipolar Disorders, vol. 12, no. 4, pp. 364-375, 2010.

[65] L. N. Yatham, I. J. Torres, G. S. Malhi et al., "The international society for bipolar disorders-battery for assessment of neurocognition (ISBD-BANC)," Bipolar Disorders, vol. 12, no. 4, pp. 351-363, 2010. 
[66] J. M. Thompson, P. Gallagher, J. H. Hughes et al., "Neurocognitive impairment in euthymic patients with bipolar affective disorder," The British Journal of Psychiatry, vol. 186, pp. 32-40, 2005.

[67] J. K. Rybakowski and A. Suwalska, "Excellent lithium responders have normal cognitive functions and plasma BDNF levels," International Journal of Neuropsychopharmacology, vol. 13, no. 5, pp. 617-622, 2010.

[68] J. M. Goldstein, M. Jerram, R. Poldrack et al., "Sex differences in prefrontal cortical brain activity during fMRI of auditory verbal working memory," Neuropsychology, vol. 19, no. 4, pp. 509-519, 2005.

[69] J. S. Janowsky, B. Chavez, and E. Orwoll, "Sex steroids modify working memory," Journal of Cognitive Neuroscience, vol. 12, no. 3, pp. 407-414, 2000.

[70] J. Jogia, D. Dima, and S. Frangou, "Sex differences in bipolar disorder: a review of neuroimaging findings and new evidence," Bipolar Disorder, vol. 14, no. 4, pp. 461-471, 2012.

[71] A. Vance, N. Hall, M. A. Bellgrove, M. Casey, F. Karsz, and P. Maruff, "Visuospatial working memory deficits in adolescent onset schizophrenia," Schizophrenia Research, vol. 87, no. 1-3, pp. 223-227, 2006.

[72] S. L. Barrett, C. Kelly, R. Bell, and D. J. King, "Gender influences the detection of spatial working memory deficits in bipolar disorder," Bipolar Disorders, vol. 10, no. 5, pp. 647-654, 2008.

[73] A. Vaskinn, K. Sundet, C. Simonsen, T. Hellvin, I. Melle, and O. A. Andreassen, "Sex differences in neuropsychological performance and social functioning in schizophrenia and bipolar disorder," Neuropsychology, vol. 25, no. 4, pp. 499-510, 2011.

[74] D. C. Glahn, C. E. Bearden, M. Barguil et al., "The neurocognitive signature of psychotic bipolar disorder," Biological Psychiatry, vol. 62, no. 8, pp. 910-916, 2007.

[75] C. E. Mackay, E. Roddick, T. R. Barrick et al., "Sex dependence of brain size and shape in bipolar disorder: an exploratory study," Bipolar Disorders, vol. 12, no. 3, pp. 306-311, 2010.

[76] P. W. Burgess, "Theory and methodology in executive function research," in Methodology of Frontal and Executive Function, P. Rabbit, Ed., pp. 81-116, Psychology Press, Hove, UK, 1997.

[77] J. K. Zubieta, P. Huguelet, R. L. O’Neil, and B. J. Giordani, "Cognitive function in euthymic bipolar I disorder," Psychiatry Research, vol. 102, no. 1, pp. 9-20, 2001.

[78] E. R. Larson, P. K. Shear, R. Krikorian, J. Welge, and S. M. Strakowski, "Working memory and inhibitory control among manic and euthymic patients with bipolar disorder," Journal of the International Neuropsychological Society, vol. 11, no. 2, pp. 163-172, 2005.

[79] I. I. Gottesman and T. D. Gould, "The endophenotype concept in psychiatry: etymology and strategic intentions," The American Journal of Psychiatry, vol. 160, no. 4, pp. 636-645, 2003.

[80] K. N. Fountoulakis, E. Vieta, C. Bouras et al., "A systematic review of existing data on long-term lithium therapy: neuroprotective or neurotoxic?" International Journal of Neuropsychopharmacology, vol. 11, no. 2, pp. 269-287, 2008.

[81] B. S. Diniz, R. Machado-Vieira, and O. V. Forlenza, "Lithium and neuroprotection: translational evidence and implications for the treatment of neuropsychiatric disorders," Neuropsychiatric Disease and Treatment, vol. 9, pp. 493-500, 2013.

[82] E. Bora, S. Vahip, F. Akdeniz et al., "The effect of previous psychotic mood episodes on cognitive impairment in euthymic bipolar patients," Bipolar Disorders, vol. 9, no. 5, pp. 468-477, 2007.
[83] A. P. Wingo, T. S. Wingo, P. D. Harvey, and R. J. Baldessarini, "Effects of lithium on cognitive performance: a meta-analysis," Journal of Clinical Psychiatry, vol. 70, no. 11, pp. 1588-1597, 2009.

[84] C. Bowden and V. Singh, "Bipolar disorders: treatment options and patient satisfaction," Neuropsychiatric Disease and Treatment, vol. 2, no. 2, pp. 149-153, 2006.

[85] G. M. Goodwin, A. Martinez-Aran, D. C. Glahn, and E. Vieta, "Cognitive impairment in bipolar disorder: neurodevelopment or neurodegeneration? An ECNP expert meeting report," European Neuropsychopharmacology, vol. 18, no. 11, pp. 787-793, 2008 . 


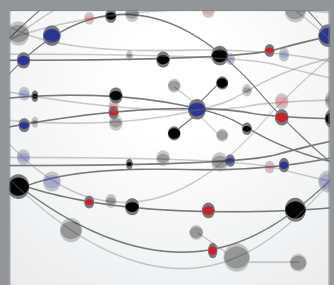

The Scientific World Journal
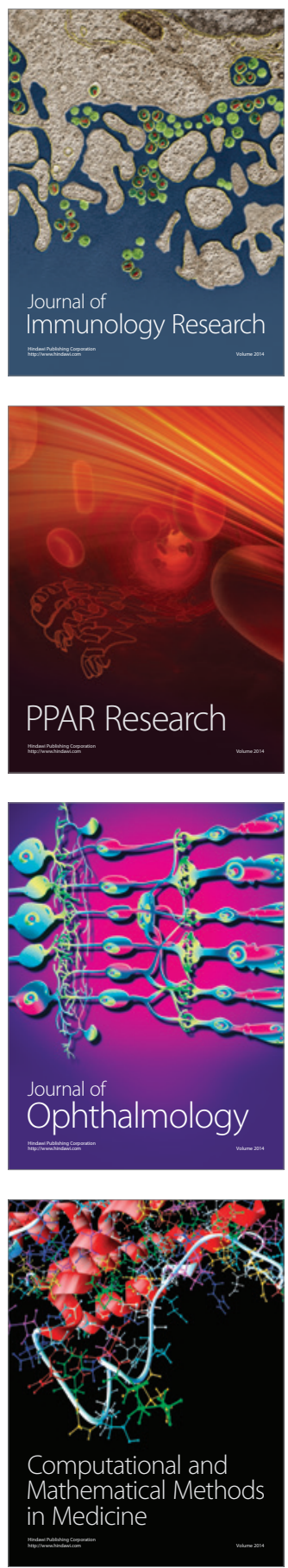

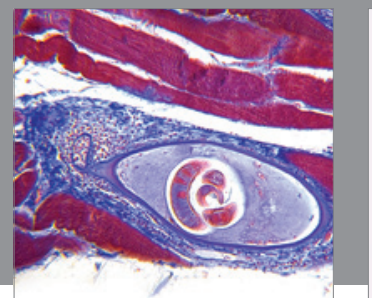

Gastroenterology

Research and Practice
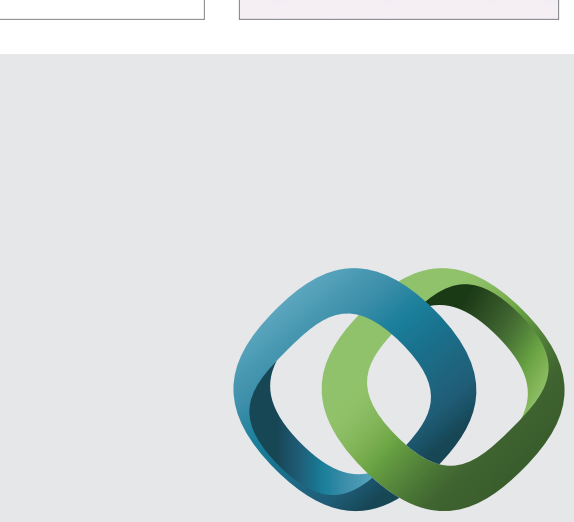

\section{Hindawi}

Submit your manuscripts at

http://www.hindawi.com
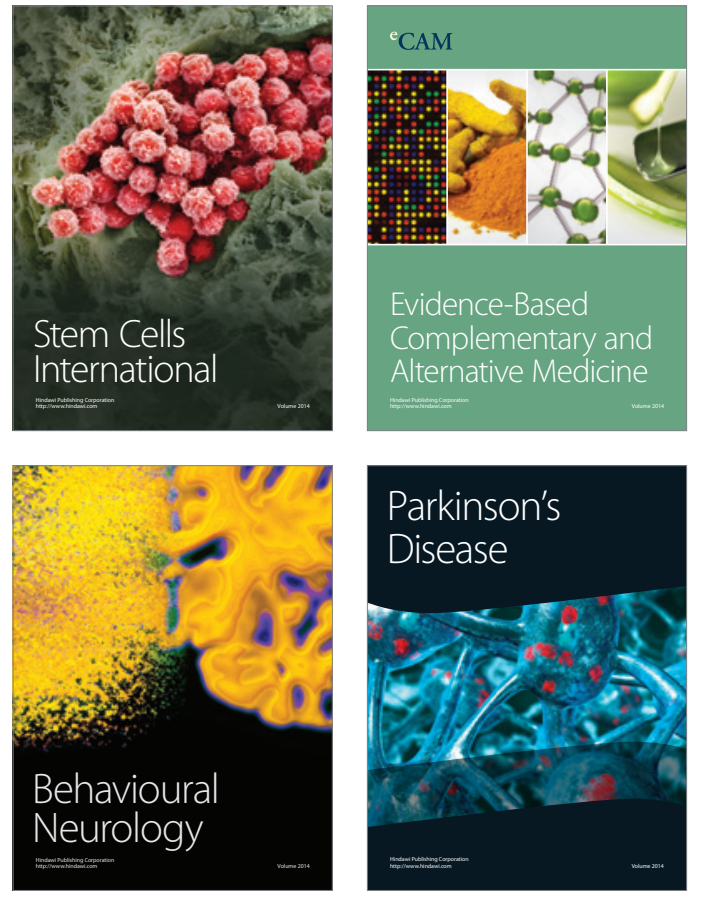
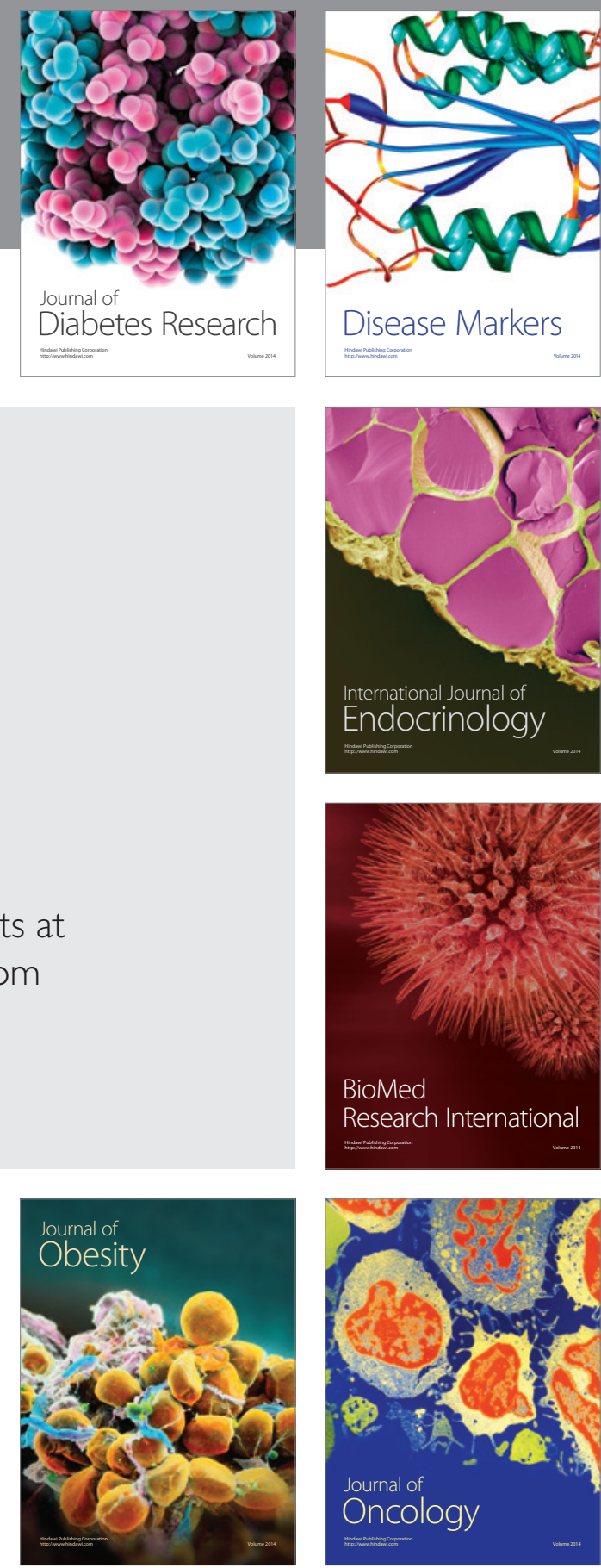

Disease Markers
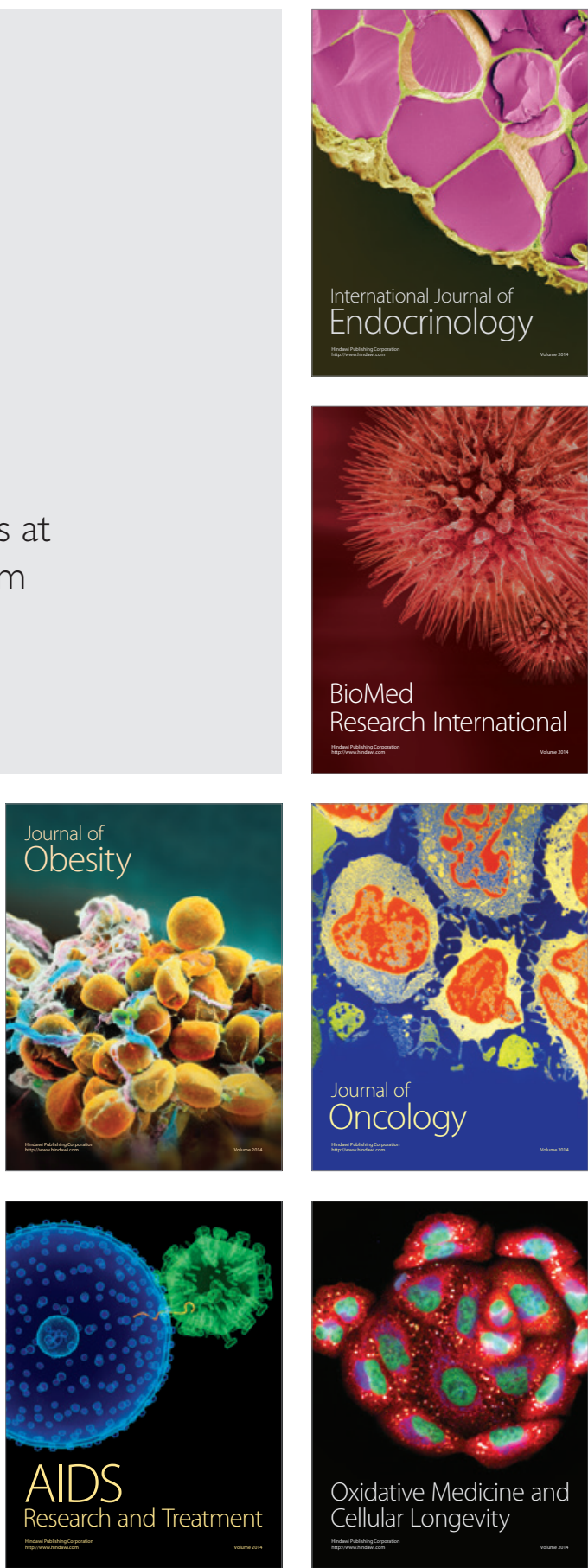